\title{
INSTITUIÇÕES FORMAIS, CIDADANIA E SOLIDARIEDADE COMPLEXA ${ }^{1}$
}

José Maurício Domingues

As formações sociais contemporâneas têm se caracterizado por mutações profundas em suas formas de sociabilidade. Pluralização das identidades, individualismo, novas formas de conceber e praticar a solidariedade social, o surgimento de novos movimentos sociais e culturais são os aspectos mais salientes e plenos de sentido que se pode localizar nessa transformação de largo alcance. As instituições formais republicanas sofrem por toda parte o impacto profundo dessas transformações, com o que se apresentam impasses, inovações e necessidades a serem atendidas, se se quer que instituições formais estatais e cidadania não vivam em mundos crescentemente apartados. Afinal, boa parte das instituições republicanas sobre as quais se alicerça a democracia contemporânea (fundamentalmente liberal, porém sobretudo na Europa bastante influenciadas ainda pelo compromisso social-democrata do segundo pós-guerra do século XX) foram geradas tendo em vista estruturas sociais

1. Este texto tem como ponto de partida a participação na pesquisa Projeto Brasil 3 Tempos: 2007, 2015, 2022 - realizada no IUPERJ para o Núcleo de Assuntos Estratégicos (NAE) da Presidência da República, em 2004. 
pronunciadamente distintas das atuais. Em que medida o Brasil participa desse processo? Se o faz, crença que articula este texto, em que medida suas instituições formais se mostram aptas a responder a esse desafio? Em que medida, por outro lado, problemas antigos desse encaixe entre sociedade e estado se repõem ou são superados, seja no plano da representação, em seus diversos níveis, seja no plano da implementação das políticas públicas?

Este texto terá como objetivo sugerir respostas a essas perguntas, embora seja a rigor mais prospectivo que uma abordagem empírica e normativa do problema. $\mathrm{O}$ que não quer dizer que não seja analiticamente orientado ou, menos ainda - ao contrário -, que não parta das transformações concretas para exatamente perseguir possíveis soluções democráticas para as novas questões assim engendradas. Para lograr aquele objetivo, faz-se portanto necessário inicialmente delinear a natureza e aquilatar a 10 extensão daquelas mudanças. A sessão a seguir ocupar-seá dessa tarefa. A seguinte tratará da articulação entre as instituições formais e a cidadania. Uma breve conclusão inquirirá sobre outras possibilidades de desenvolvimento institucional possíveis ${ }^{2}$. Não se trata de uma perspectiva normativa, porém sim de inquirir sobre impasses e localizar alternativas que neste momento podem ainda mostrarse de maneira incipiente. O núcleo do artigo aponta para a possibilidade da formação de uma "solidariedade complexa” no Brasil contemporâneo.

\section{Novas sociabilidades e a autonomia dos sujeitos}

O século XX assistiu a uma enorme transformação da sociedade brasileira, naquilo que se pode classificar como um processo de "modernização conservadora". Inicialmente a grande propriedade fundiária manteve-se intocada, mas a

2. Os argumentos aqui dispostos se apóiam em parte em Domingues (2002). 
dialética do processo de modernização enfim a alcançou. Ao completar-se esse processo, portanto, nas últimas décadas daquele século, a população brasileira se via livre das amarras das formas de dominação pessoal, livre assim para vender sua força de trabalho e, dentro dos limites de uma sociedade de classes bastante autoritária e de pobreza disseminada, organizar a sua vida como bem entendesse. Isso implicou a possibilidade de construção de identidades de caráter muito mais "eletivo" que anteriormente, bem como a construção de laços de sociabilidade também de livre escolha em grande medida. Em alguns núcleos industriais principais do país a identidade operária se firmou e organizações sindicais ajudaram a organizar a vida desses trabalhadores que assim se viam integrados, ademais a um projeto de país em que, de uma maneira ou de outra, eram assinalados como atores fundamentais. O corporativismo foi por muitos anos inclusive o padrão institucional que garantiu a inclusão e o controle dessa parcela da população, enquanto outros permaneciam como meros pobres, rurais ou urbanos, mais ou menos à margem do mundo oficial, no caso dos analfabetos impedidos inclusive de participar das instituições "poliárquicas” (para usar a expressão de Dahl) - isto é, democráticas por contarem com eleições em larga medida livres e com a possibilidade de expressão e debate de opiniões igualmente amplas, porém sem que o topo da pirâmide seja de acesso generalizado ou direto, de fato incluindo um sistema de dominação por parte dos grupos políticos-administrativos, o que autores de correntes mais realistas (desde Weber) vêem assinalando, para não falar de sua ligação com as classes mais poderosas do capitalismo brasileiro e internacional. As instituições poliárquicas brasileiras, isto não obstante e em que pese a vigência de ditaduras militares nesse período, foram pouco a pouco se firmando e afirmando o que se poderia chamar de "dialética do controle" entre governantes e governados, entre aqueles 
que "dominam", no sentido forte do termo, as instituições políticas e a cidadania em geral ${ }^{3}$.

A transição à democracia, a partir do inicio dos anos 80, foi em parte o fechamento definitivo daquele ciclo de modernização conservadora - estando então garantida a liberdade dos indivíduos e grupos e o acesso da quase totalidade da população, agora inclusive os analfabetos, àquelas instituições poliárquicas, tendo lugar também o fim do arranjo corporativo vigente até então. Podemos dizer que a consecução do processo de modernização conservadora levou a um desencaixe generalizado dos sujeitos, uma vez que foram lançados no plano nacional sem mais restrições à sua movimentação ou laços de subordinação e identidades rígidas localizadas em um espaço-tempo fechado. A cidadania, elemento-chave daquele universo poliárquico, se apresentou assim, para todos, não obstante restrições severas no plano civil, por exemplo, como o reencaixe identitário

12 fundamental, individual e coletivamente. Como, aliás, sói acontecer na modernidade de forma geral.

Ao mesmo tempo, uma significativa mutação social começava a se processar, nos planos da identidade e das práticas sociais, internamente assim como sob a influência de fatores externos. Uma individualização crescente da vida social por um lado se processava, ligada em parte ao declínio das identidades de classe (calcado em transformações reais dos sujeitos sociais no Brasil, mas também na perda de adesão global de que a idéia de uma classe operária unificada fazia sentido e podia ter ademais um papel histórico especial), à emergência das mulheres como sujeitos mais autônomos, a uma crescente independização dos jovens e à redução relativa da população rural (ela mesma em grande medida já muito distinta daquela que conhecemos há alguns decênios). Por outro lado, uma necessidade de reencaixes

3. Ver Giddens (1985), para esse feixe de conceitos. 
coletivos menos abstratos que aquele oferecido pela cidadania se apresentou. Combinado à liberdade de movimentação dos sujeitos e à falta de uma identidade englobante mais forte, esses reencaixes se afirmaram como de caráter plural. Essa complexidade ocasiona uma perda de eficácia relativa das instituições tradicionais dos sistemas poliárquicos, assim como de outras expressões da modernidade política, como o corporativismo e o neocorporativismo.

\section{Cidadania e sistema formal}

Desde a chamada "Revolução de 30" até o final da ditadura militar em meados dos anos 80, um dos elementos fundamentais que articulavam a população ao estado e suas instituições formais eram dados pelo corporativismo, embora para muitos as instituições da poliarquia, sobretudo através do sistema eleitoral e do judiciário, tivessem um papel em muitos momentos decisivo a cumprir. Outros simplesmente permaneciam excluídos deste universo, imerso em formas de dominação pessoal no campo, que se estendiam às periferias geográficas e sociais dos centros urbanos, onde corporativismo e poliarquia vigiam com pesos variáveis entre esses dois momentos. Após este sistema haver entrado em colapso, o que solda cidadãos e estado hoje?

De início é mister esclarecer que não se trata de um problema atinente apenas ao Brasil. Em todo o mundo este tipo de questão demanda atenção de cientistas sociais e dos construtores de instituições. O fim do arranjo neocorporativo na Europa e uma crescente pluralização social têm gerado graves problemas de coordenação e solidarização social naquele continente. Quem representa o quê, ante quem, se as identidades são heterogêneas e os movimentos sociais menos centralizados, ao mesmo tempo em que as esferas públicas se pluralizam e setorializam? (Streeck e Schmmitter, 1991; Eder, 2001.) O que fazer se resposta a isso aparece por exemplo na atuação de um poder judiciário que tende 
a ocupar na sociabilidade e na política um espaço para além do que seria democraticamente razoável? (Garapon, 1996.) No restante da América Latina isso é ainda mais gritante, por exemplo na Argentina, com o surgimento de movimentos sociais - em particular os piqueteiros - bastantes distintos do tradicional peronismo sindical, com seu corte também corporativista; ou no México, com a perda em grande medida do controle - também baseado no corporativismo - do Partido Revolucionário Institucional (PRI) sobre os movimentos sociais, ainda que aí o corporativismo sobreviva com mais viço, dado seu acordo com as forças políticas emergentes originalmente à direita do PRI, como o Partido Ação Nacional (PAN). Em ambos esses países, uma resposta importante à crise e declínio do corporativismo tem sido dada por formas variadas de clientelismo, embora outras formas de relação entre estado e sociedade venham sendo ensaiadas por alguns movimentos sociais (ver por exemplo 14 Maneiro, 2006). De todo modo, esses ensaios se dão a partir da pluralização dessas coletividades e da articulação, por agregação em grande medida, de suas demandas e propostas, antes que desde o ponto de vista de uma coletividade principal já dada, como em algum momento operou a classe operária tradicional, ou pelo menos o que aqueles que pretendiam representá-la apresentavam como seus interesses e propostas (ver Garavito, Barret e Chávez, 2005).

Há, evidentemente, algo de muito positivo no ocaso do corporativismo, uma vez que ele implicou em grande medida um controle autoritário sobre os sindicatos e a população em geral. Mas, se uma autonomização importante dos movimentos sociais teve lugar, que dizer da construção da solidariedade social, da representação de interesses e dos pontos de contato entre estado e sociedade? Sem dúvida, uma perspectiva revolucionária, que aposta em uma ruptura total do modelo moderno-capitalista de sociedade, não deveria se importar com esse tema, pois lhe interessaria 
somente a agudização dos conflitos sociais. Se não compramos a idéia de que hoje o socialismo propriamente dito seria possível (não obstante, a menos a meu ver, ser nele que a modernidade encontraria a realização de seus principais valores) faz-se necessário então apostar em uma nova configuração da cidadania, da social-democracia, dos laços de solidariedade social, da representação de interesses dos diversos e pluralizados setores e movimentos sociais. As instituições tradicionais da poliarquia decerto contribuem nessa direção, como o fizeram ao longo da história moderna. O Brasil em particular, hoje, apresenta inclusive alguns elementos interessantes de aprofundamento de algumas dessas instituições poliárquicas - ampliação da participação eleitoral, assim como de demandas e possibilidades de fortalecimento e abrangência do sistema judiciário (Nicolau, 2004; Vianna, 2002). O problema é que, por definição, essas são instituições onde o cidadão comparece, com exceções que em geral não passam pela auto-representação (como a defesa dos direitos difusos pelo Ministério Público), enquanto indivíduo. Ou seja, interesses coletivos (em sentido não exclusivamente pecuniários e/ou auto-referidos) e auto-sustentados não têm espaço nesse sistema de representação de corte, apesar de tudo, liberal clássico.

O republicanismo clássico - e mesmo a perspectiva social-democrata liberal de Marshall (1950) - tende a tomar a sociedade como um agregado de indivíduos; os quais são percebidos, na face que importa à república, como absolutamente homogêneos. Direitos universais referir-se-iam a cidadãos cujas diferenças concretas não interessavam. Inspirado na divisão marxiana entre citoyen (potencialmente universal, o que se dá na prática com o fim do voto censitário, baseado na renda ou em posses) e bourgeois, que ocultava os interesses concretos deste último, articulei a noção de cidadania à de abstração real (expressão luckasiana), em que seus portadores são tomados como indivíduos sem qualida- 
des específicas (Marx, 1844; Domingues, 2002, caps. 3-4) ${ }^{4}$. O corporativismo de fato foi além disso e já reconhecia, e tratou de regular, coletividades sociais, de classe e profissionais (Vianna, 1976; Santos; 1979). Nesse sentido, foi doutrina sem dúvida inovadora no século XX, em uma sociedade contudo ainda não tão complexa quanto a atual. Esta, em sua pluralização de identidades, individuais e coletivas, demanda que se vá além do corporativismo, porém também do republicanismo tradicional, em que a uma sociedade relativamente simples correspondia, mediante ao fim e ao cabo a universalização dos direitos, uma solidariedade também relativamente simples, conquanto inclusiva.

É aqui que deve intervir uma nova perspectiva. Pois, a despeito de seus traços autoritários, o corporativismo teve o mérito de avançar para além de interesses individuais e buscar organizar a cidadania de forma a que suas identidades e interesses coletivos se expressassem de forma a 16 gerar solidariedade e participação sustentada, que não se resume a períodos eleitorais, nem se estiola na perseguição de metas particularistas, incluindo também a participação em pelo menos alguns dos processos administrativos, para além da representação e da deliberação ${ }^{5}$. Além do mais, ao esgotamento desse arranjo se somam os impasses dos partidos políticos hoje, uma forma também clássica de organizar projetos coletivos, a qual se encontra igualmente desgastada, dada a própria complexificação da vida social, que dificulta a expressão dessas identidades e interesses coletivos de forma organizada, assim tornando as agremiações par-

4. Vale agregar a isto a passividade implicada pelas abstrações reais, do que o aspecto instituído da cidadania compartilha, conquanto o oposto seja verdadeiro quanto a seu aspecto instituinte, que se funda nas lutas sociais.

5. Não incluir este aspecto me parece ser o limite de propostas que apontam para a noção de "democracia deliberativa", ainda que os avanços que tais práticas propõem sejam de óbvia relevância para superar os problemas aqui assinalados, assim como, implícito antes que explícito neste texto, os impasses que a complexidade social engendra para a democracia direta e o republicanismo participativo tradicional. Ver Avritzer (2002). 
tidárias crescentemente um mero aparelho para ação das burocracias e dos políticos profissionais. Isso ocorre no Brasil e nos demais países latino-americanos, reproduzindo fenômeno mais geral da civilização moderna contemporânea (Cavarozzi e Abal Medina, 2002; Santos, 1988, cap. 4). Qual o seu destino não é totalmente claro ainda, mas dificilmente serão instrumentos fortes o bastante para organizar a cidadania; por outro lado, decerto serão apenas parciais na mediação entre sociedade e estado.

Isto posto, parece-me claro que é preciso avançar em alguma outra direção. A evolução da modernidade, elevando a complexidade social e tornando a sociedade - inclusive a brasileira - mais heterogênea e mais opaca para o estado, demanda novas respostas do ponto de vista político e das instituições. Novos desenhos institucionais podem e devem ser pensados desde esse ponto de vista.

Tanto o corporativismo clássico como o neocorporativismo europeu social-democrata basearam-se em mecanismos hierárquicos - com a coordenação da ação social realizando-se mediante comandos verticais. A crescente autonomização das pessoas e das coletividades (a ampliação de sua liberdade de ação e movimento, a despeito de desequilíbrios gritantes para exercê-la e a manutenção de duros sistemas de dominação) implica que identidades e interesses não só se pluralizam como também se torna mais difícil, se não impossível, controlá-los de cima para baixo. De forma geral, nos pontos em que demandas variadas surgem e a criatividade social se exerce de maneira sustentada ou episódica, são os mecanismos de rede, baseados na colaboração voluntária, que têm proporcionado novas formas de coordenação da ação social e a articulação, em planos mais concretos, da solidariedade social. Experiências do judiciário e de ramos dos executivos em diversos planos (da segurança pública à re-qualificação profissional, da gestão de recursos públicos a implementação de programas culturais) indicam 
um caminho promissor nesse sentido, ao articular estado e movimentos sociais e culturais (Vianna, 2002; Coelho e Nobre, 2005).

O problema aqui é que, de modo geral, essas redes entre estado e sociedade abarcam setores relativamente reduzidos da população. Isso é verdadeiro seja no que tange a sua abrangência hoje, pois esse mecanismo não se generalizou ainda como talvez fosse mais adequado; nem tampouco, em si, ele dá resposta a todas as questões. Isso ocorre porque, exatamente por focar em interações concretas e subjetividades particulares, dando conta de problemas específicos, essas experiências de articulação entre estado e sociedade dificilmente teriam a capacidade de cobrir um espectro mais largo e mais abstrato da sociedade, dando conta de questões mais gerais ${ }^{6}$. Abordagens universalistas, portanto, devem manter-se no que se refere às instituições formais. Os desenhos poliárquicos e republicanos clássicos 18 - que a meu ver devem obviamente ser pensados incluindo não apenas os direitos civis e políticos, mas também os sociais - devem impor-se paralelamente à proliferação das redes de coordenação entre estado e sociedade. A incorporação da população à institucionalidade formal deve assim passar por essas duas dimensões. Combinadas elas podem contribuir para gerar o que se poderia chamar de uma solidariedade complexa.

Reencaixes mais concretos e reencaixes mais abstratos, formas de coordenação mais particulares e formas de coordenação mais gerais se articulariam de modo a responder, de um ponto de vista institucional-formal, porém também incorporando, em seu maior particularismo e concretude, instituições de caráter informal, à complexidade acrescida da vida social contemporânea, nela incluída a dinâmica

6. A exceção aqui talvez seja a esfera pública, na qual uma solidariedade complexa se tece, baseada tanto nas redes quanto nas hierarquias e nos mercados, para além de uma pura ação comunicativa como quereria Habermas. 
social do Brasil do século XXI. A expressão de interesses e demandas, realizada de forma autônoma, não precisaria perder-se no mero conflito com os aparelhos de estado ou na auto-satisfação de movimentos que terminam por circunscrever-se ao jogo de sua própria identidade, quando não acabam meramente cooptados. É a esta dinâmica social e mediante esses mecanismos que responderia a complexificação também da solidariedade social. Nem o retorno a um estado social-democrata tradicional, sonho de muitos na esquerda desiludidos com o marxismo revolucionário, embora continuem a utilizar-se de sua linguagem, nem as falácias do neoliberalismo e sua crença a um possível retorno ao mercado como senhor absoluto da vida social, com o auxílio apenas de um estado mínimo, o que não se verifica sequer nos países onde logrou hegemonia. Um redesenho criativo das instituições formais brasileiras é o que parece ser mais favorável à democracia e ao desenvolvimento do país.

\section{Palavras finais}

A modernidade emergiu configurada, ao menos idealmente, como uma sociedade de indivíduos atomizados e livres, que encontravam no estado o lócus e agente da paz entre eles. A crise da primeira fase dessa modernidade liberal, na virada do século XIX para o XX, levou a uma sociedade em que o papel do estado aumentou, ao mesmo tempo em que as grandes coletividades sociais - em particular os trabalhadores organizados - eram reconhecidas e assimiladas na construção de uma solidariedade mais ampla e inclusiva. Uma crise se seguiu sem tardar ao apogeu, nos anos 195060, dessa fase da modernidade, estatalmente organizada: os anos 1970-80 viram o esgotamento do modelo do Estado do Bem-Estar Social, do keynesianismo, do corporativismo bem como do neocorporativismo, e do nacional-desenvolvimentismo, que se mostraram incapazes de lidar com a complexificação da vida social. 
A esta altura a crise foi já superada e, em meio à instabilidade inerente a este tipo de formação social, desdobramse os elementos de uma terceira fase, que chamei alhures de "modernidade de articulação mista" (Domingues, 2002, cap. 8). Nesta, ou reconstruímos os laços sociais de solidariedade, processo em que a remodelagem das instituições formais é decisiva, ou a fragmentação, a irresponsabilidade e a violência tendem a imperar. Uma outra solução, aquém da reconstrução dos laços solidários, é o modelo norte-americano de violenta repressão policial e generalizado encarceramento das populações que não se vêem atendidas pelo mercado capitalista (como trabalhadores e/ou consumidores), no caso dos Estados Unidos, populações predominantemente negras. Não seria possível, naquele país, o estado, em conjunto com as lideranças dos amplos setores negros da sociedade, democrática e colaborativamente, logo com mais legitimidade, buscar projetos que evitassem a aplica20 ção daquele modelo? Creio que sim, mas então se trata de opções de cunho clara e diretamente político.

A terceira fase da modernidade está aberta a disputas, assim como estiveram as duas outras anteriores. Populações mais livres e plurais tendem a ser mais difíceis de tratar, pois aceitam menos o tacão do comando hierárquico. Para incorporá-las são necessários reconhecimento identitário e de suas demandas, assim como processos concretos capazes de dar-lhes voz organizada e processar expectativas e reivindicações. O dilema socialismo ou barbárie parece não estar mesmo na ordem do dia. Se ao tipo de solidariedade social visado por aquele não se abre muito espaço neste momento, a ameaça desta última nem por isso se faz menos real. Seria difícil exagerar a importância das instituições democráticas formais renovadas no sentido de evitar que venha a prevalecer. Elas têm papel crucial a cumprir no estabelecimento de formas avançadas e necessárias solidariedade complexa contemporaneamente. 
Assim, se queremos avanços democráticos e participativos em uma república de cidadãos livres e plurais, parece-me imprescindível construir alternativas na direção que busquei acima sugerir. Desta forma, uma solidariedade social complexa, inclusiva e voltada para a liberdade, talvez possa firmar-se e ampliar o exercício da cidadania para além do republicanismo e do liberalismo entre nós.

\section{José Maurício Domingues}

é professor de Sociologia do Iuperj

\section{Referências bibliográficas}

AVRITZER, Leonardo. Democracy and the public space in Latin America. Princeton: Princeton University Press, 2002.

CAVAROZZI, Marcelo \& MEDINA, Juan Abal (Orgs.). El asedio a la política. Los partidos latinoamericanos en la era neoliberal. Rosário: Homo Sapiens, 2002. COELHO, Vera Schattan P. \& NOBRE, Marcus (Orgs.). Participação e deliberação. Teoria democrática e experiências institucionais no Brasil contemporâneo. São Paulo: Editora 34, 2005.

DOMINGUES, José Maurício. Interpretando a modernidade. Imaginário e instituições. Rio de Janeiro: Editora FGV, 2002a.

(2002b) "A dialética da modernização conservadora e a nova história do Brasil”. In: Ensaios de sociologia. Belo Horizonte: Editora UFMG, 2004.

EDER, Klaus. "Zur transformation nationalstaatlicher Öfentlichkeit in Europa”. Berliner Journal für Soziologie, vol. 2, 2001.

GARAPON, Antoine. Le gardien des promesses. Paris: Odile Jacob, 1996. GARAVITO, César A. Rodríguez, BARRET, Patrik S. e CHAVEZ, Daniel (Orgs.). La nueva izquierda en América Latina. Sus orígenes y trayectoria futura. Bogotá: Colombia, 2005.

GIDDENS, Anthony. The nation state and violence. Cambridge: Polity, 1985. MANEIR0, Maria. "Os movimentos sociais na América Latina. Uma perspectiva a parir das relações do Estado com a sociedade civil”. In: DOMINGUES, José Maurício e MANEIRO, Maria (Orgs.). América Latina hoje. Teorias e interpretações. Rio de Janeiro: Civilização Brasileira (no prelo), 2006.

MARSHALL, T. H. (1950). "Citizenship and social class". In: Class, citizenship and social development. Garden City, NY: Double Day \& Co, 1964. 
MARX, Karl (1844). Zur Judenfrage, in Marx E Engels, Werke, vol. 1. Berlim: Dietz, 1956.

NICOLAU, Jairo. História do voto no Brasil. Rio de Janeiro: Zahar, 2004. GUILHERME DOS SANTOS, Wanderley. Cidadania e justiça. A politica social na ordem brasileira. Rio de Janeiro: Campus, 1979.

Vértice, 1988. . Paradoxos do liberalismo. Rio de Janeiro: Iuperj e São Paulo: STREECK, Wolfgang e SCHMMITTER, Phillip C. "From National Corporatism to Transnationalk Pluralism: Organized Interests in the Single Eurpean Market”. In: Politics and Society, vol. 19, 1991.

VIANNA, Luiz Werneck. Liberalismo e sindicato no Brasil. Rio de Janeiro: Paz e Terra,1976.

. (Org.). A democracia e os três poderes no Brasil. Belo Horizonte:

Editora UFMG, 2002. 


\section{D)}

\section{INSTITUIÇÕES FORMAIS, CIDADANIA E SOLIDARIEDADE COMPLEXA}

JOSÉ MAURÍCIO DOMINGUES

Este artigo visa discutir certas limitações do republicanismo tradicional poliárquico no Brasil, buscando soluções para os impasses da representação e da participação tal como se põem hoje. Não se trata de uma perspectiva normativa, mas de inquirir sobre problemas e localizar alternativas que neste momento podem ainda mostrar-se de maneira incipiente. $\mathrm{O}$ núcleo do artigo aponta para a possibilidade da formação de uma "solidariedade complexa" no Brasil contemporâneo.

Palavras-chave: Instituições Poliárquicas; Republicanismo; Brasil; Modernidade; Solidariedade Complexa.

\section{FORMAL INSTITUTIONS, CITIZENSHIP, AND COMPLEX SOLIDARITY}

This article aims at some problems of the traditional poliarchic republicanism in Brazil, searching solutions for its difficulties on the issues of representation and participation. Not meant as a normative proposal, the article just enquiries alternatives which, at this moment, can not be more than probings. The core of these enquiries points out to the formation of a "complex solidarity" in contemporary Brazil.

Keywords: Poliarchic Institutions; Republicanism; Brazil; Modernity; Complex Solidarity. 